\title{
Is Fluoroscopy-guided Suprascapular Nerve Block Better Than Other Techniques?
}

\author{
Department of Anesthesiology and Pain Medicine, School of Medicine, Hanyang University, Guri, Korea
}

Jae Hang Shim, MD

\section{LETTER TO EDITORS}

Suprascapular nerve blockade (SSNB) is a simple and safe technique that provides relief from various types of shoulder pain since first described in 1941 by Wertheim and Rovenstein [1]. The Posterior approach has usually been performed for SSNB with or without C-arm fluoroscope.

Kang et al. described a new anterior approach for SSNB with fluoroscope [2]. They used anatomical landmarks including the coracoid process, scapular spine, shaft of the clavicle and suprascapular notch. A small volume of local anesthetic was injected and effective pain relief was achieved. They mentioned that their new technique had some advantages including effective block with a small dose of local anesthetics, more accurate placement of the tip of needle in the scapular notch and fewer complications such as pneumothorax and hematoma.

$\mathrm{C}$-arm fluoroscope has been widely used for precise pain management and effective treatment [3-5]. However, frequent use of the fluoroscopy-guided technique causes severe health problems.

Recently, the reduction of irradiation exposure to the operator has been a key issue among pain physicians [6].

The most effective method to reduce irradiation exposure is to use a technique that does not require equip- ment that utilizes radiation. Sono-guided techniques are frequently performed for various nerve blocks among clinicians. Sono-guided SSNB has been recently reported in the literature $[4,5,7]$. Some alternative techniques using ultrasound and the good successful rates of SSNB have also been reported [4]. These techniques make the sonoguided procedure the best choice for SSNB. Higher resolution and better accurate machines have been developed. Ultrasound is safe from irradiation and the equipment is simple to use. Sono-guided SSNB could become more popular among physicians due to it being radiation free and accurate. If it is at your bedside, it is a safe bet you will choose it.

\section{REFERENCES}

1. Wertheim HM, Rovenstine EA. Suprascapular nerve block. Anesthesiology 1941; 2: 541-5.

2. Kang SS, Jung JW, Song CK, Yoon YJ, Shin KM. A new anterior approach for fluoroscopy-guided suprascapular nerve block - a preliminary report -. Korean J Pain 2012; 25: $168-72$.

3. Peng PW, Wiley MJ, Liang J, Bellingham GA. Ultrasoundguided suprascapular nerve block: a correlation with fluoroscopic and cadaveric findings. Can J Anaesth 2010; 57 : 143-8.

Received November 15, 2012. Accepted November 16, 2012.

Correspondence to: Jae Hang Shim, MD

Department of Anesthesiology and Pain Medicine, School of Medicine, Hanyang University, 249-1 Kyomun-dong, Guri 471-701, Korea Tel: +82-31-560-2390, Fax: +82-31-563-1731, E-mail: jhshim@hanyang.ac.kr

(c) This is an open-access article distributed under the terms of the Creative Commons Attribution Non-Commercial License (http:// creativecommons.org/licenses/by-nc/3.0/), which permits unrestricted non-commercial use, distribution, and reproduction in any medium, provided the original work is properly cited.

Copyright (c) The Korean Pain Society, 2013 
4. Siegenthaler A, Moriggl B, Mlekusch S, Schliessbach J, Haug M, Curatolo M, et al. Ultrasound-guided suprascapular nerve block, description of a novel supraclavicular approach. Reg Anesth Pain Med 2012; 37: 325-8.

5. Harmon D, Hearty C. Ultrasound-guided suprascapular nerve block technique. Pain Physician 2007; 10: 743-6.
6. Park PE, Park JM, Kang JE, Cho JH, Cho SJ, Kim JH, et al. Radiation safety and education in the applicants of the final test for the expert of pain medicine. Korean $\mathrm{J}$ Pain 2012; 25: 16-21.

7. Chan CW, Peng PW. Suprascapular nerve block: a narrative review. Reg Anesth Pain Med 2011; 36: 358-73. 